\title{
Nicotine in E-Cigarettes Dysregulates Pulmonary Inflammation and MMP-12 Expression without Effecting Respiratory Syncytial Virus Virulence
}

\author{
Hannah Goldenberg ${ }^{1}$, Brais Perez Gandara ${ }^{2}$, Jessica Perez Perez ${ }^{2}$, Andrew Bramante ${ }^{1}$, \\ Robert Foronjy ${ }^{2}$, Abdoulaye J. Dabo ${ }^{2}$, Edward Eden ${ }^{3}$, Josué Sznitman ${ }^{4}$ \\ and Patrick Geraghty $2, *$ (D) \\ 1 Greenwich High School, Greenwich, CT 06830, USA; hannah.goldenberg@greenwichschools.org (H.G.); \\ andrew_bramante@greenwich.k12.ct.us (A.B.) \\ 2 Department of Medicine, State University of New York Downstate Health Sciences University, \\ Brooklyn, NY 11205, USA; Brais.PerezGandara@downstate.edu (B.P.G.); \\ Jessica.PerezPerez@downstate.edu (J.P.P.); Robert.Foronjy@downstate.edu (R.F.); \\ Abdoulaye.Dabo@downstate.edu (A.J.D.) \\ 3 Division of Pulmonary and Critical Care Medicine, Mount Sinai West, NY 10019, USA; \\ Edward.Eden@mountsinai.org \\ 4 Department of Biomedical Engineering, Technion-Israel Institute of Technology, Haifa 32000, Israel; \\ sznitman@bm.technion.ac.il \\ * Correspondence: Patrick.Geraghty@downstate.edu; Tel.: +1-718-270-3141
}

Academic Editor: Paul Zarogoulidis

Received: 24 November 2020; Accepted: 10 January 2021; Published: 14 January 2021

\begin{abstract}
The safety of electronic cigarettes (e-cigarettes) is a major topic of discussion. The key goals of this study were to examine the contents of e-cigarette vapor and determine if nicotine altered inflammatory responses against respiratory syncytial virus (RSV) infection. E-cigarette vapor was passed through a hollow 3D-model of an adult lung, and gas chromatography detected over 50 compounds passed through the 3D model, including nicotine, propylene glycol (PG), ethanol, methanol, and diacetyl. The murine alveolar macrophage cell line MH-S cells were exposed to nicotine and e-cigarette vapor with and without nicotine. Nicotine significantly induced the expression of matrix metalloprotease (Mmp) 12 and reduced expression of Ifn $\beta$ and Tnf $\alpha$. To examine the role of nicotine in lung defense against RSV infection, A/J mice were exposed to PBS, e-cigarette vapor with and without nicotine for 2 months before RSV infection. E-cigarette vapor did not influence RSV infection-induced animal weight loss, RSV infectivity, airway hyperresponsiveness during methacholine challenge, or immune cell infiltration into the lungs. However, e-cigarette vapor containing nicotine enhanced obstruction and induced secretion of MMP12 and reduced levels of Ifn $\beta$ and TNF $\alpha$. In conclusion, nicotine in vaping products modulates immune responses that may impact the lungs during a respiratory infection.
\end{abstract}

Keywords: e-cigarettes; nicotine; respiratory syncytial virus

\section{Introduction}

Electronic nicotine delivery systems (ENDS), such as electronic (e)-cigarettes, are frequently utilized by former smokers to quit tobacco smoking by switching to ENDS [1]. However, an increasing number of young adults become addicted to nicotine by using ENDS products, which could influence addiction to other nicotine products. According to the National Institute on Drug Abuse, approximately $70 \%$ of teenagers are introduced to e-cigarette advertising. Equally, the safety of ENDS usage is now in question [2], especially with the recent vaping-associated pulmonary injury (EVALI) outbreak and 
growing evidence of potential harmful effects of vaping [3]. There is also mounting animal model data suggesting that inhalation of vapors generated in ENDS could result in lung damage [4]. Within the U.S., the Food and Drug Administration (FDA) recently issued an enforcement policy on unauthorized flavored cartridges in ENDS, with particular emphasis on targeting minors [5]. Therefore, additional studies focusing on the characterization and potential biological impact of contents of the vapor generated by ENDS products are required. Equally, we know little of the long-term impact these products have on lung homeostasis.

The liquid within ENDS primarily contains propylene glycol (PG), vegetable glycerin (VG), glycerol, an assortment of flavors, and nicotine. However, researchers have detected between 60 to 113 chemicals [6,7], including formaldehyde, acetaldehyde, acrolein, glyoxal, acetone, propanal, crotonaldehyde, butanal, and methylglyoxal [8-10]. The vapor of PG and VG in ENDS increases lipid accumulation in alveolar macrophages and alters type II pneumocyte surfactant homeostasis, resulting in reduced inflammation [3] that makes the lungs more susceptible to viral infections, including influenza [3] and human rhinovirus [11]. The flavoring within ENDS products can alter allergy responses to human dust mite in mice [12]. ENDS usage is also linked to changes in DNA methylation, immune responses, and neurological issues to offspring in utero in animal models $[13,14]$. Vitamin $\mathrm{E}$ acetate is detected in bronchoalveolar lavage fluid (BALF) samples isolated from EVALI patients [15]. Exposing mice to aerosols generated from vitamin E acetate, a mixture of PG-VG, enhanced albumin concentrations in BALF, leukocyte frequency, and lipid loaded macrophages around the alveoli [4].

We know little about the contents of the vapor used in e-cigarettes, or if the contents observed in the vapor influence immune responses to infection. Here we examined the components observed in e-cigarette vapor directly after puffing from the e-cigarette device and after passes through an artificial oral cavity and bronchi model. Equally, we examine several immune responses in an alveolar macrophage cell line and mice exposed to e-cigarette vapor before infection with the respiratory syncytial virus (RSV). We utilized the RSV infection model as RSV infections are observed in infants, but also in older adults [16]. Therefore, we expect to observe constitutions of e-cigarette vapor that could contribute to altered responses to respiratory infections.

\section{Experimental Section}

\subsection{Gas Chromatography (GC)-Flame Ionization Detector (FID) and Fourier-Transform Infrared Spectroscopy} (FTIR) Analysis

To collect e-cigarette nebulized vapors, a syringe-based vapor collection device was constructed. A T-connector was placed between the syringe and a JUUL e-cigarette (containing a JUUL Kiwiberries Ice pod) containing a 1:1 ratio of PG:VG (Figure 1). The syringe was used to draw in $40 \mathrm{~mL}$ of vapor in $4 \mathrm{~s}$ from one puff generated from the e-cigarettes. Although this method is manual, a 4-s puff was utilized as suggested based on previously e-cigarette topography [17]. In order to mimic a smoking regime, three 4-s puffs separated by 10-s intervals between puffs were manually drawn into the syringe. Subsequent recondensed vapor was utilized for gas chromatography analysis and cell experiments. E-cigarette vapor $(0.5 \mu \mathrm{L})$ was injected into a PerkinElmer Autosystem XL Gas Chromatograph, with a Flame Ionization Detector and a Supelco Equity-1 column $(30 \mathrm{~m} \times 0.25 \mathrm{~mm}, 0.25 \mu \mathrm{m}$ film $)$ at a He carrier flow rate of $2 \mathrm{~mL} / \mathrm{min}$ at an injector and FID detector temperature of $250^{\circ} \mathrm{C}$. The oven temperature was initiated at $35^{\circ} \mathrm{C}$ for $1 \mathrm{~min}$ and ramped to $260^{\circ} \mathrm{C}$ at $11^{\circ} \mathrm{C} /$ minute. The instrument parameters were adjusted to a reduced (from 40:1) split ratio of 10:1, to compensate for gas-phase sampling. 

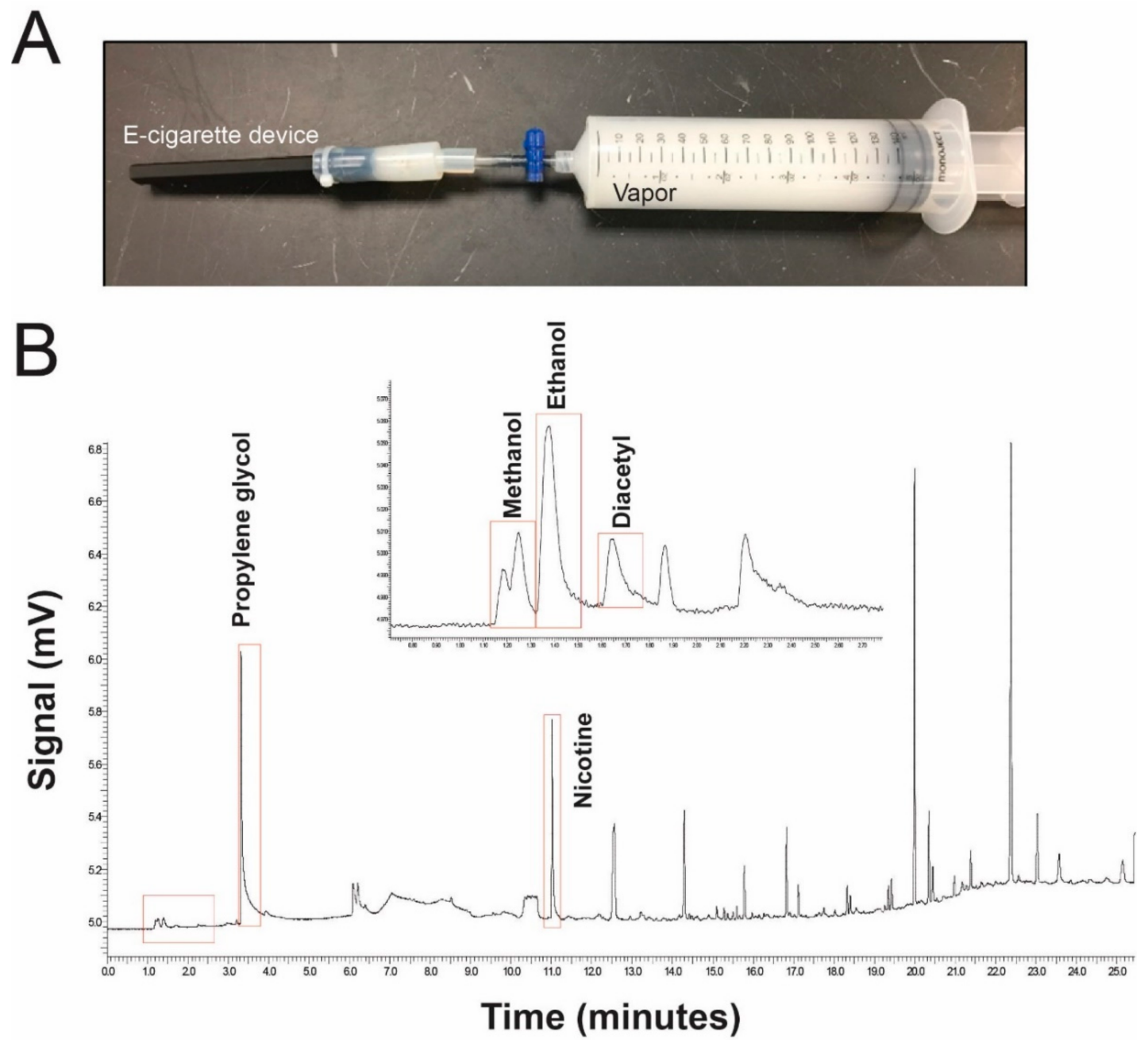

Figure 1. Gas chromatogram of e-cigarette vapor. (A) Vapor was collected from an e-cigarette in a syringe-based vapor collection device. (B) $0.5 \mu \mathrm{L}$ e-cigarette vaping liquid was introduced to the gas chromatograph and yielded over 50 peaks. Several chemicals were identified, including methanol (1.25 $\mathrm{min})$, ethanol (1.4 $\mathrm{min})$, diacetyl (1.65 $\mathrm{min})$, propylene glycol (3.45 $\mathrm{min})$, and nicotine (11 $\mathrm{min})$. The circled region is expanded to view peaks for methanol, ethanol, and diacetyl.

\subsection{Simulation of Vape Inhalation in a 3D Artificial Lung Cavity}

To mimic artificial lung inhalation with sufficient force to actuate the e-cigarette, and intake a typical portion of e-cigarette vapor, a two-chamber vacuum system was created (Figure 2A,B). A vacuum pump (1) was used to first lower the isolated pressure of a $4.5 \mathrm{~L}$ vacuum chamber. (2) Once $\sim 70 \mathrm{kPa}$ pressure was established, (3) a separation valve between the vacuum chamber and the $5.5 \mathrm{~L}$ artificial lung cavity (preheated to $37^{\circ} \mathrm{C}$ ) was opened (4), and the sudden drop in pressure simulated $2 \mathrm{~L} / \mathrm{s}$ inhalations of the e-cigarette vapor (5). To simulate a short inhalation of vapor, three "puffs" of e-cigarette vapor were passed through the artificial oral cavity, trachea, and bronchi, as previously described [18]. Samples were collected from three 4-s puffs separated by 10-s intervals at the end of the artificial bronchi and were analyzed via GC-FID. 


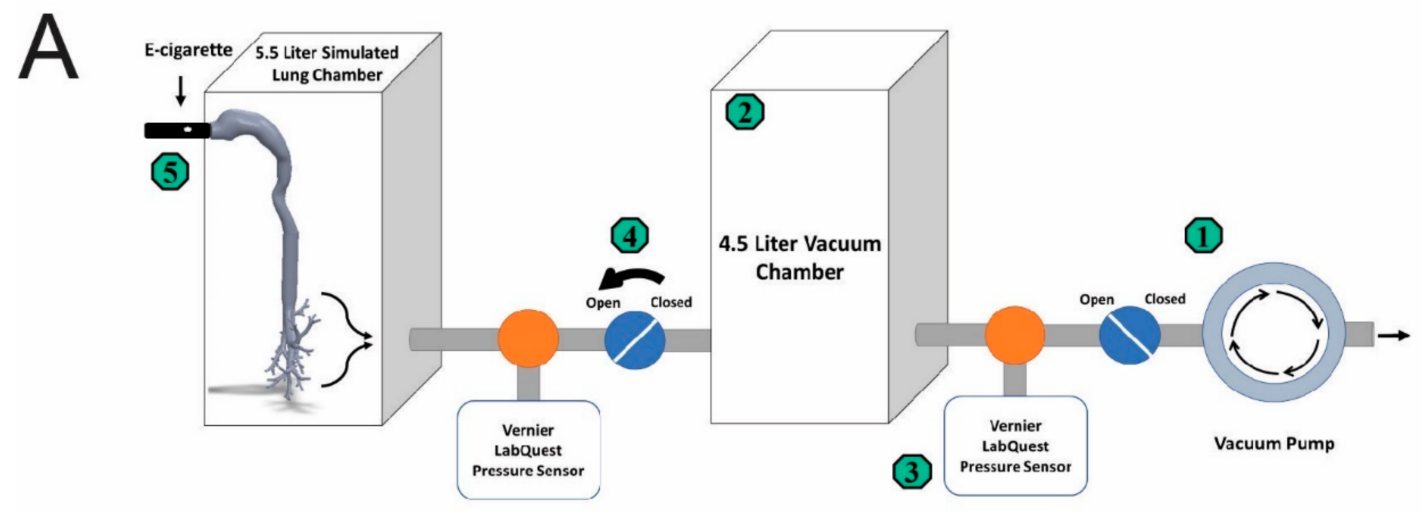

B
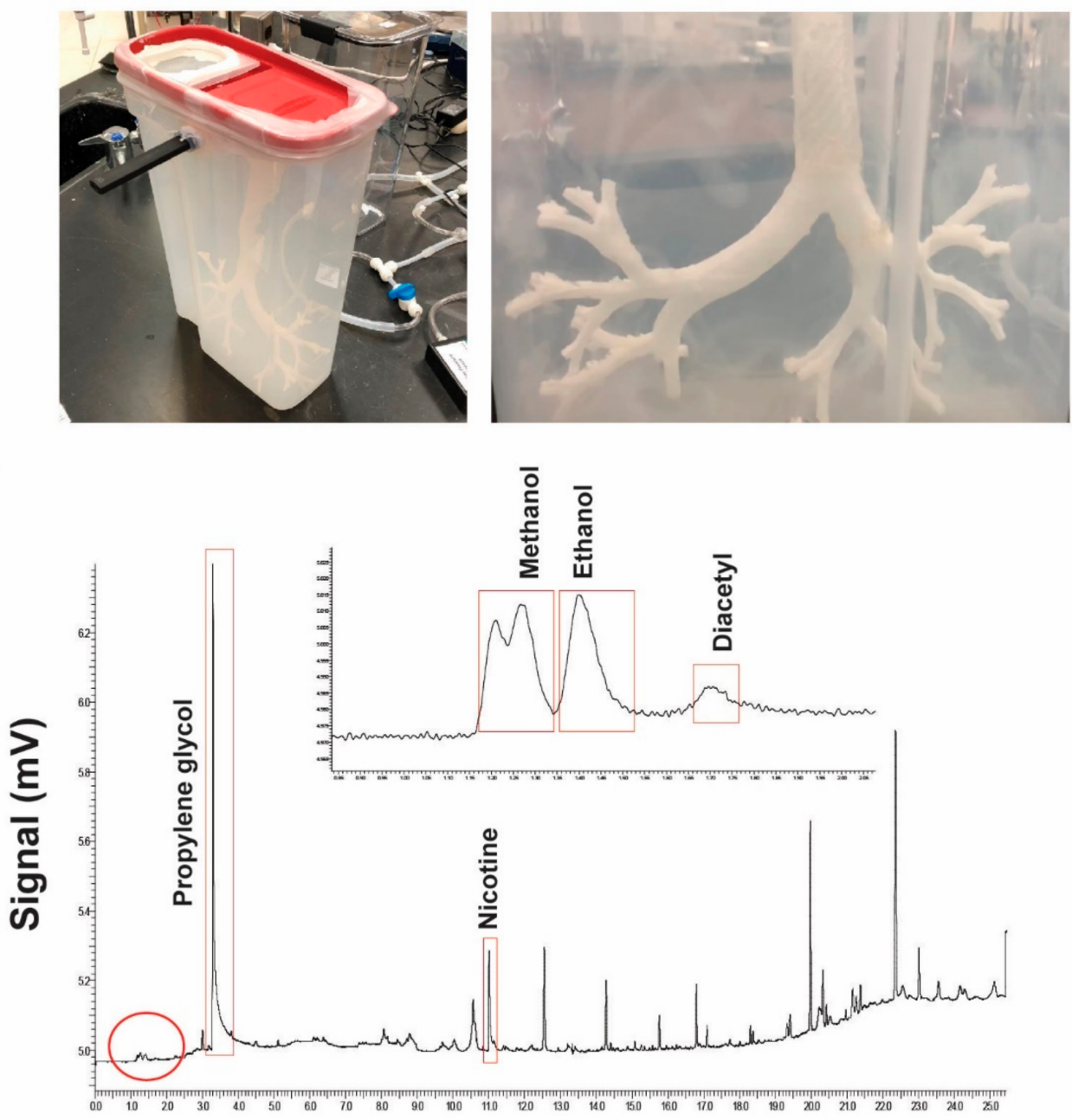

\section{Time (minutes)}

Figure 2. A 3D artificial lung structure captures e-cigarette vapor. (A) A schematic of the e-cigarette exposure set-up. (B) Images of the e-cigarette and 3D airways set-up. (C) $0.5 \mu \mathrm{L}$ e-cigarette vaping liquid that passed through the 3D model was introduced to the gas chromatograph and yielded over 50 peaks.

\subsection{Cell Line}

Murine alveolar macrophages from cell line MH-S (CRL-2019; American Type Culture Collection (ATCC), Manassas, VA, USA) were maintained in RPMI 1640 medium (ATCC) supplemented with 10\% 
fetal bovine serum and 1\% streptomycin-penicillin-glutamate solution (Life Technologies, Carlsbad, CA, USA). Cells were grown at $37^{\circ} \mathrm{C}$ in a humidified $5 \% \mathrm{CO}_{2}$ incubator and $1 \times 10^{6} \mathrm{cells} / \mathrm{mL}$ were seeded in 12-well culture clusters $12 \mathrm{~h}$ prior to exposure to various concentrations of e-cigarette vapor or nicotine. For RNA and media collection, cells were treated with $1 \%(v / v)$ PBS, $1 \%(v / v)$ e-cigarette vapor (with and without nicotine) in media, or $1 \mu \mathrm{M}$ nicotine. In vitro cell viability was determined by lactate dehydrogenase (LDH) released into media using a commercially available assay (Sigma-Aldrich, St. Louis, MO, USA) and non-toxic levels of each stimulus was selected following LDH release analysis.

\subsection{Target Analysis}

RNA was isolated using the Qiagen RNeasy kit, and cDNA was reverse transcribed using the Applied Biosystems high capacity cDNA kit. qPCR was performed on the Bio-Rad CFX384 real-time system using validated Taqman probes (Life Technologies/Applied Biosystems, Foster City, CA, USA). qPCR results are represented as relative quantification (RQ). Gene expression was normalized to Actb and Gapdh. Mouse MMP12 and TNF $\alpha$ were examined in BALF using beads assays (MILLIPLEX MAP MMP Magnetic Bead and MILLIPLEX Cytokine Magnetic Bead Panels, Millipore Sigma, Billerica, MA, USA) with the Bio-Rad Bio-Plex 200 system.

\subsection{In Vivo Inhaled Exposure to E-Cigarette Vapor}

This study was performed in strict accordance with the recommendations in the Guide for the Care and Use of Laboratory Animals of the National Institutes of Health and Institutional Animal Care and Use Committee (IACUC) guidelines. Mount Sinai West's Institutional Animal Care and Use Committee approved the protocol. For 2 months (5 days/week), 8-week-old male and female A/J mice (Jackson Labs) were whole-body exposed to vapor generated from $0.4 \mathrm{~mL}$ of PBS or e-cigarette (PG and VG 50/50; American eLiquid Store, Wauwatosa, WI, USA) containing 0 or 18-mg/mL nicotine (American eLiquid Store). During exposures, up to 12 animals were housed in a mouse aerosol pie cage (Braintree Scientific, Braintree, MA, USA), and vapor was generated from $0.4 \mathrm{~mL}$ of PBS alone or e-cigarette (PG:VG with and without nicotine) and delivered to all twelve animals. Puffs were separated by 60-s intervals. After 2 months of exposure to the vapor, mice were infected with the RSV strain A2 (ATCC, Manassas, VA, USA; \#VR-1540) and were euthanized 7 days post-infection. For the infection, mice were anesthetized by intraperitoneal injection of a mixture of ketamine and xylazine. Animals were intranasally administered $1 \times 10^{6}$ plaque-forming units (pfu) of RSV or mock. Animals were weighed daily. The expression of $R S V N$ was determined by qPCR. The following primers were

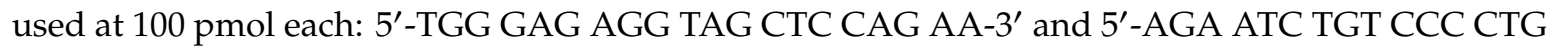
CTG CTA-3'.

\subsection{Expiratory Measurements}

Mice were anesthetized with an intraperitoneal (ip) injection of ketamine/xylazine hydrochloride solution (100/10 mg/kg; Millipore Sigma, Burlington, MA, USA). Animals were tracheostomized and connected via an endotracheal cannula to the SCIREQ flexiVent system (SCIREQ Inc., Montreal, QC, Canada). After initiating mechanical ventilation, animals were paralyzed with a $1 \mathrm{mg} / \mathrm{kg}$ pancuronium bromide (Millipore Sigma) via ip injection and pressure-volume loops were recorded. The area under the curve (AUC) of the PV loops was calculated for each animal. PV loops and AUC were corrected for animal weights. The linear single-compartment model was also used to assess total respiratory system resistance (Rrs). Methacholine dose responses were determined as previously described [19].

\subsection{Histological Analysis}

The lungs underwent pressure-fixation, and fixed tissue was processed and H\&E stained for analysis of inflammation scoring. Briefly, the intensity of inflammation was scored on a scale of 1 to 9 . With a score of 0 corresponding to no inflammation; $1-3$, was scant cells but not forming a defined layer; $4-6$, one to three layers of cells surrounding the vessel; 7-9, four or greater layers of cells surrounding 
the vessel or bronchial. Every vascular vessel and bronchus were measured on multiple lung lobes from 3 different depths of sectioned tissue [20,21].

\subsection{Statistical Analyses}

Data are expressed as dot plots with the means \pm S.E.M highlighted. Differences between two groups were compared by Student's $t$-test (two-tailed). Experiments with more than 2 groups were analyzed by 2-way ANOVA with Tukey's post hoc test analysis. $p$ values for significance were set at 0.05 , and all significant changes were noted with *. All analysis was performed using GraphPad Prism Software (Version $6.0 \mathrm{~h}$ for Mac OS X).

\section{Results}

\subsection{E-Cigarette Vapor Contains Many Hydrocarbons}

We analyzed e-cigarette vapor using GC with Mass Spectroscopy and determined there are as many as 50 unidentified hydrocarbons present in the e-cigarette vapor (Figure 1). Attenuated Total Reflectance Fourier Transform Infrared (ATR-FTIR) spectroscopic analysis of e-cigarette vapor detected significant concentrations of propylene glycol as the solvent, and no detectable water content. Diacetyl, methanol, ethanol, and nicotine were all are present in the e-cigarette vapor.

To determine whether these vapor components passed through the airways, a 3D structure was utilized in a 2-chamber vacuum system (See Figure 2A,C). E-cigarette vapor was passed through this system and the vapor was collected at the end of the bronchi structures and GC analysis confirmed the presence of propylene glycol, nicotine, methanol, ethanol, diacetyl, and over 50 unidentified components (Figure 2D). Therefore, many of the components present in e-cigarette vapor are delivered to the airways.

\subsection{Nicotine Alters Immune Responses in a Murine Alveolar Macrophage Cell Line}

To determine if components of e-cigarette vapor could impact immune cell responses, MH-S macrophages were exposed to various concentrations of e-cigarette vapor (with or without nicotine), or nicotine. $\mathrm{LDH}$ assays were performed to identify non-toxic concentrations of e-cigarette vapor, or nicotine (Figure 3A). At non-toxic concentrations, both e-cigarette vapor with nicotine and nicotine alone increased Mmp12 expression, while significantly reducing Ifn $\beta$ and $\operatorname{Tnf} \alpha$ responses in alveolar macrophages (Figure 3B).

3.3. Exposure to E-Cigarettes Alters MMP12, IFN $\beta$, and TNF $\alpha$ Responses without Influencing RSV Virulence or Airway Hyperresponsiveness (AHR) in Mice

To determine whether e-cigarette exposure altered immune responses during infection, mice were exposed to e-cigarette vapor, with and without nicotine, 5 times weekly for 8 weeks (chronic exposure), and were subsequently infected with RSV (See Figure 4A). Interestingly, pre-exposure to e-cigarette vapor had no impact on RSV infection-induced loss of weight or RSV virulence (Figure 4B,C). Nicotine in e-cigarette vapor does alter pressure-volume loops, suggesting elevated obstruction (Figure 4D). However, RSV infection associated with AHR during a methacholine challenge did not become further elevated by e-cigarette vapor with or without nicotine (Figure 4E). 

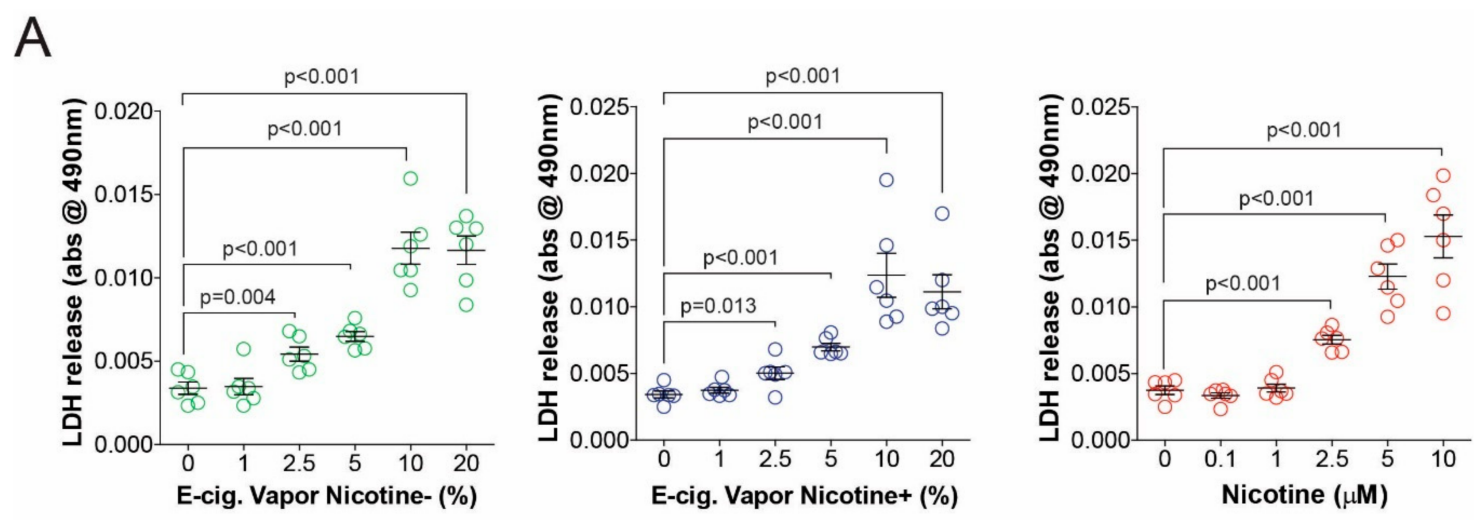

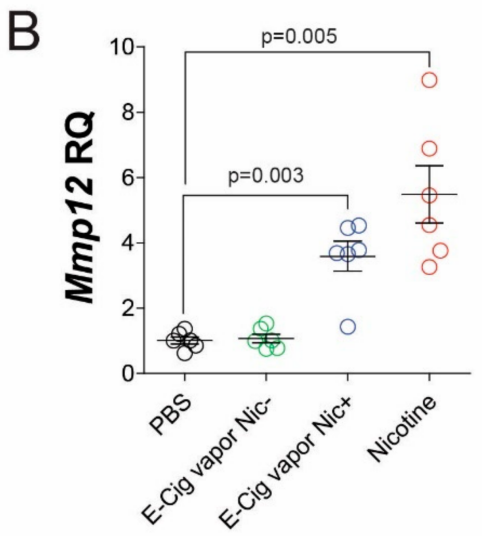

Cell treatment

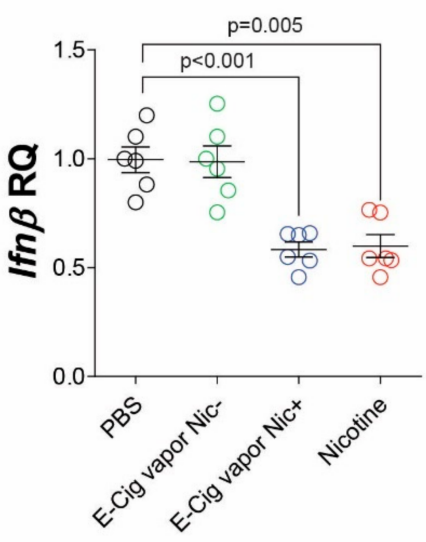

Cell treatment

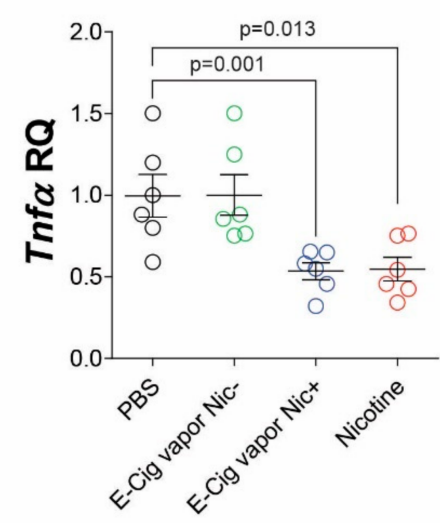

Cell treatment

Figure 3. Nicotine alters $M m p 12$, Ifn $\beta$, and Tnf $\alpha$ expressions in murine alveolar macrophage cell line MH-S cells. MH-S macrophages were seeded onto 12-well plates and media was supplemented with various concentrations of e-cigarette vapor (with or without nicotine), or nicotine. (A) Toxicity assays were performed by measuring lactate dehydrogenase (LDH) release. (B) Mmp12, Ifn $\beta$, and Tnf $\alpha$ gene expressions were determined with non-toxic concentrations of each stimuli by qPCR after 24 h exposure. Data are represented as mean \pm S.E.M., where each measurement was performed on several independent days. $p$ values are shown when comparing both treatments connected by a line, determined by ANOVA with Bonferroni posttests.

Tissue inflammation scores were recorded on lung tissues and demonstrated similar inflammation in the lungs of all RSV infected animals (Figure 5A). However, similar to the in vitro data, e-cigarette vapor increased MMP12 secretion, while significantly reducing Ifn $\beta$ expression and TNF $\alpha$ secretion in RSV infected mice (Figure 5B). 


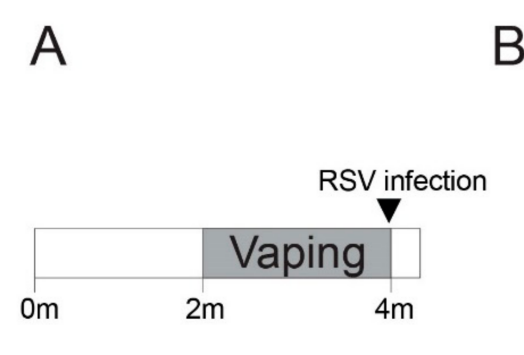

D

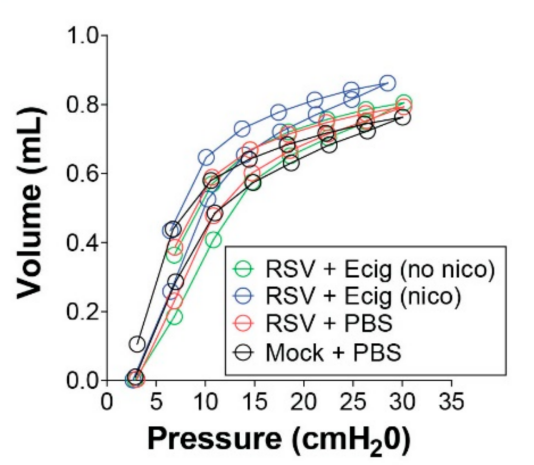

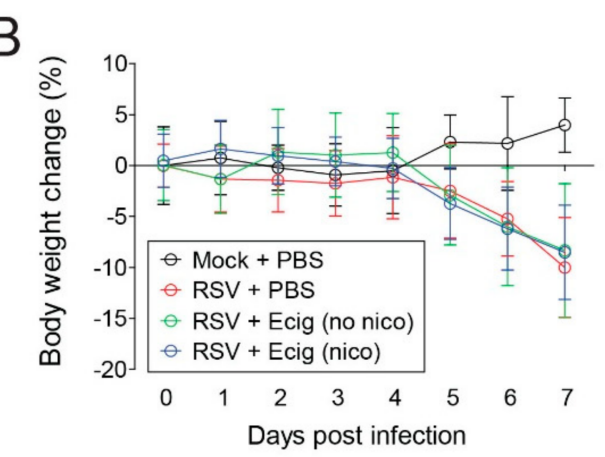

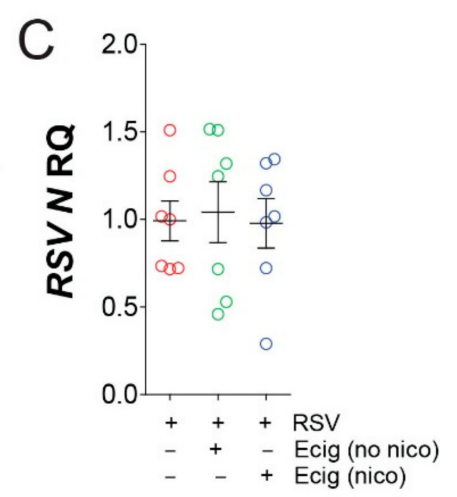

$E$

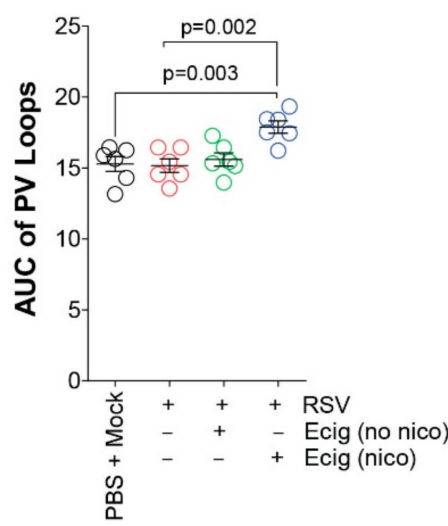

Figure 4. Pre-exposure to e-cigarettes does not influence respiratory syncytial virus (RSV) virulence or airway hyperresponsiveness (AHR) in mice. (A) A/J mice were exposed to vapor generated from PBS or e-cigarettes with or without nicotine for 2 months and subsequently infected with RSV. (B) Animal weight changes were recorded each day post RSV infection. (C) RSV N gene expression was examined in lung tissue 7 days post-infection. (D) Negative pressure-driven forced expiratory and forced oscillation technique maneuvers were performed in all animal groups. Pressure volume loops and subsequent area under the curve (AUC) of PV loops were determined in each animal and corrected for animal weight. (E) Respiratory system resistance (Rrs) measurements were recorded in animals during methacholine dosing. Data are represented as mean \pm S.E.M, where $n \geq 6$ per group. $p$ values are shown when comparing both treatments connected by a line, determined by 2-way ANOVA with Bonferroni posttests. 
A
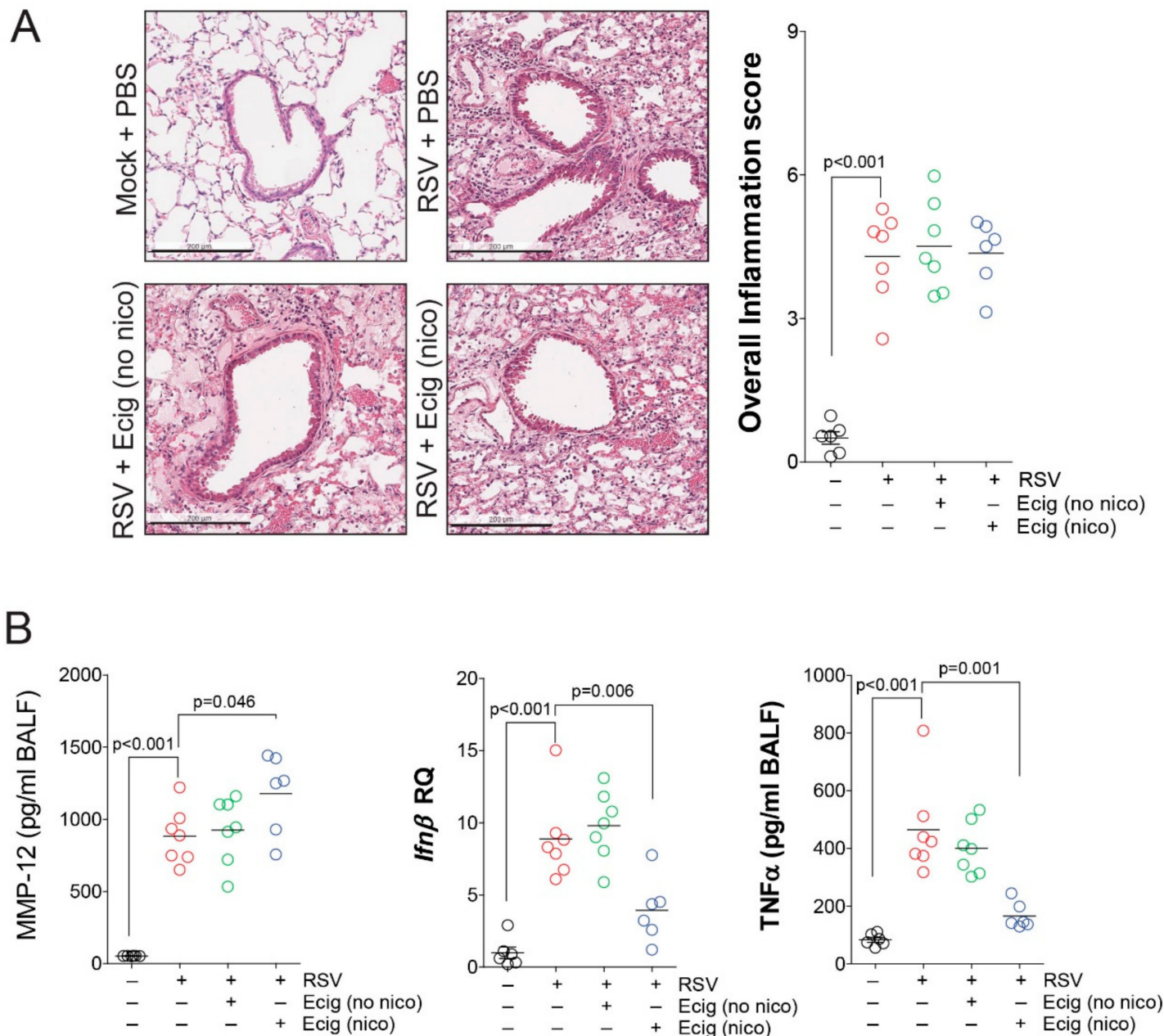

Figure 5. Pre-exposure to e-cigarettes alters MMP12, Ifn $\beta$, and TNF $\alpha$ levels during RSV infection in mice. A/J mice were exposed to vapor generated from PBS or e-cigarettes with or without nicotine for 2 months and subsequently infected with RSV. (A) Comparative histology images of the four mouse groups are presented here (scale bars $=500 \mu \mathrm{m}$ ). Inflammation scoring was performed for each animal. (B) BALF levels of MMP12 and TNF $\alpha$ were determined by Luminex assays and lung tissue Ifn $\beta$ gene expression was determined by qPCR. Data are represented as mean, where each measurement was performed with $n \geq 6$ animals per group. $p$ values are shown when comparing both treatments connected by a line, determined by ANOVA with Bonferroni posttests.

\section{Discussion}

E-cigarettes produce less environmental pollutants, lack harmful tar, and contain far fewer cancer-causing chemicals than conventional tobacco cigarettes [22,23]. However, the recent EVALI outbreak and the growing evidence of potential harmful effects of vaping [3] and animal models data [4] suggest that ENDS products have the potential to induce harm to users. This study shows that vapor produced by e-cigarettes passes through the airways of an artificial model. Nicotine was observed to be one of the major immune-modulating components of e-cigarette vapor, with a single-dose of e-cigarette vapor and nicotine significantly reducing Ifn $\beta$ and Tnf $\alpha$ expression responses while increasing $M m p 12$ expression in alveolar macrophage cell line. Therefore, a short exposure to recondensed vaping liquid modulated these changes and remained altered in our chronic exposure model in mice. Thus, the findings from this study demonstrate that e-cigarette vapor contains many compounds in the airways that could influence immune responses to pulmonary viral infections.

In our GC analysis, we utilized flavored e-cigarettes, but did not use the flavored e-cigarettes for our cell or animal model as the flavorants alone can trigger several responses [24]. Due to the 
recent ban on flavors in e-cigarettes that target young users this year in the USA [5], we have primarily focused on the other components of the e-cigarette liquid in our in vitro cell and in vivo mouse studies. However, while we focus on non-flavorants, we do want to stress the importance of detecting diacetyl vapors in our GC analysis using flavored e-cigarette liquids and diacetyl is associated with flavorings-related lung disease, such as bronchiolitis obliterans [25]. In vitro diacetyl exposure models of epithelium results in significant activation of matrix remodeling pathways [26]. Another research group demonstrated 163 differentially expressed genes in primary normal human bronchial epithelial cells following exposure to diacetyl, using RNA-sequencing [27]. The majority of the genes were involved in cytoskeletal and cilia processing. Therefore, vaporized diacetyl could directly impact ciliary function.

Our group previously demonstrated that exposure to nicotine-containing e-cigarette modulated inflammation, AHR, and lung tissue destruction in non-infected mice [28]. Others have reported that mice exposed to ENDS vapor did not develop pulmonary inflammation or emphysema [3]. In this current study, we further observed nicotine-dependent signaling playing a major role in several parameters of lung homeostasis. Our study examines 7 days post-infection, both male and female mice, and a lower concentration of nicotine that is utilized in the Madison et al. study [3]. We do observe lung obstruction with nicotine-containing vaping, but nicotine did not enhance RSV-induced AHR. Our data nicely aligns with Madison et al. study [3] regarding immune modulation of e-cigarette vapor and possible immune modulation in virally infected lungs. Many regard nicotine as an anti-inflammatory agent, but it must be in the context of all parameters, such as nicotine administration (injected, dermal, or inhaled into the lungs), sex, age, tissue sampling, the concentration of nicotine, infection status, and underlying condition. Equally, nicotine hinders the hydration of mucus [29], promotes $\mathrm{Ca}^{2+}$ influx in airway smooth muscle cells [30], blocks neutrophil apoptosis [31], and induces pro-inflammatory dendritic cell responses [32]. Therefore, inhalation of nicotine may not align with nicotine responses observed with other delivery approaches and impacts several critical functions within the lungs. The Madison et al. study [3] also demonstrates the influence of e-cigarette vapor on lung lipid balance and function of innate immunity, with changes in pulmonary surfactant, airway phospholipid pools and suppressed expression of the surfactant proteins (SP), Sp- $a$ and $S p-d$. These changes were observed to be primarily due to the e-cigarette vapor independent of nicotine. Alteration of surfactant and phospholipids could further impact alveolar injury during infection. SP-A and SP-D play critical roles in lung defense against RSV infections [33]. Additional studies are needed to address the potential impact of e-cigarettes on surfactant and phospholipid mediated alveolar injury.

With conventional cigarette smoke exposure, we previously observed elevated MMP12 and suppressed Ifn $\beta$ that coincide with increased RSV persistence [34]. In this current study, we see an alteration in TNF $\alpha$ and MMP12 secretions and suppression of Ifn $\beta$ expression with e-cigarette vapor, without changes in RSV virulency. Our study is limited in sampling at one time-point in mice, as others have observed weight, virulency, and inflammatory score changes when examined on multiple days post-infection [35]. Equally, we previously reported elevated inflammation (IL-6 and IL-8) in human cells and mice exposed to e-cigarettes containing nicotine without a viral infection [28]. Sussan et al. observed a reduction in IL-17A, TNF $\alpha$, and IFN $\gamma$ due to e-cigarette exposure prior to H1N1 infection, and no changes in IL-6 and MCP1 [35]. Similar to conventional cigarette smoke, e-cigarette vapor appears to modulate immune responses rather than inducing or reducing inflammation. In terms of e-cigarette vapor inhibiting IFN $\beta$, this could aid RSV infectivity as RSV surface proteins reduce anti-viral type I IFN expression, thereby promoting virus replication [36]. Importantly, infants with severe RSV bronchiolitis have lower nasal viral load and type-I IFN levels than moderately ill children [37]. Interestingly, combined TNF $\alpha$ and IFN $\beta$ treatment of RSV-infected A549 epithelial cells prevented RSV replication [38]. Interestingly, IFN $\beta$ is the current standard treatment for patients with multiple sclerosis (MS), and exposure to cigarette smoke is an environmental risk factor for MS [39], but possibly not due to nicotine [40]. IFN $\beta$ can regulate antigen presentation and T-cell proliferation, and can alter 
cytokine and MMP expression [41]. Therefore, altered IFN $\beta$ responses may impact several responses beyond RSV infections.

Although TNF $\alpha$ is linked to allergic exacerbations in RSV mice models [42], loss of TNF $\alpha$ signaling with inhibitory antibodies results in enhanced weight loss and slower recovery time in RSV-infected mice [43]. TNF $\alpha$ is primarily produced by monocytes and macrophages and interacts primarily with two receptors, TNFR1 and TNFR2. It plays a major role in apoptosis, cell differentiation, proliferation, and migration of cells causing an inflammatory reaction [44]. Inhibition of TNF $\alpha$ is reported to results in several possible side effects, such as hepatotoxicity, malignity, greater risk for infection, immunogenicity, and cutaneous reactions [45]. Additionally, high levels of TNF $\alpha$ are known to play a role in several inflammation associated diseases, such as rheumatoid arthritis. Therefore, subdued TNF $\alpha$ responses observed here may impact other processes. Finally, it is well documented that MMP12 plays a major role in numerous pulmonary diseases [46], and enhancing MMP12 levels in RSV infections could result in RSV bronchiolitis [47,48]. Interestingly, MMP12 has opposing anti-viral properties intracellularly versus extracellularly. Intracellular MMP12 regulates NFKBIA transcription, resulting in IFN $\alpha$ secretion to protect the host, while extracellular MMP-12 cleaves the IFN- $\alpha$ receptor 2 binding sites of IFN- $\alpha$; thereby, preventing an unchecked immune response [49]. MMP12 is also known to play a major role in embryonic development, reproduction, and tissue remodeling, as well as in disease processes, such as arthritis, metastasis, and several neurological diseases [50]. Therefore, maintaining a normal level of MMP-12, TNF $\alpha$, and IFN $\beta$ may be critical in RSV-associated bronchiolitis and other responses throughout the body.

There are several limitations that need to be discussed here. First, we only report changes in Ifn $\beta$ in mice by qPCR. IFN- $\beta$ protein levels were not detectable in BALF. Additionally, we only sample at one time point in the animals. Additional time points may identify virulence or inflammation changes within this model. Equally, we utilized a single dose in vitro model. This was undertaken to determine whether an acute exposure to nicotine and e-cigarette vapor could alter MMP-12, TNF $\alpha$ and IFN $\beta$ responses or whether tissue remodeling was required to change these parameters. The concentration of nicotine we administered to the mice is lower than many commercially available products (18 versus $36 \mathrm{mg} / \mathrm{mL}$ ). Therefore, additional concentration studies would be of interest. Our cell and in vivo studies are all mouse based rather than human. There may be several different nicotine responses unique to mice compared to humans. Finally, we manually sampled the e-cigarette vapor which may not best represent the puffing/vaping regime of ENDS users.

In summary, our study demonstrates that many compounds generated in e-cigarette vaping pass through the oral cavity and bronchioles that could contribute to altered immune responses to respiratory infection. Therefore, nicotine is a major player in modulating immune responses in the lungs.

Author Contributions: Conceptualization, H.G., R.F., A.B., E.E., J.S., and P.G.; methodology, H.G., B.P.G., J.P.P., A.B., A.J.D., and P.G.; validation, H.G., R.F., A.B., E.E., J.S., and P.G.; formal analysis, H.G., B.P.G., J.P.P., A.B., and P.G.; investigation, H.G., B.P.G., J.P.P., A.B., and P.G.; resources, P.G.; data curation, H.G., B.P.G., J.P.P., A.B., and P.G.; writing - original draft preparation, H.G. and P.G.; writing-review and editing, All authors assisted in the editing of the manuscript; supervision, A.B., E.E., J.S., and P.G.; funding acquisition, P.G. All authors have read and agreed to the published version of the manuscript.

Funding: This work was supported by grants made available to P.G. Flight Attendant Medical Research Institute (YCSA113380 and CIA160005) and the Alpha-1 Foundation (493373 and 614218).

Institutional Review Board Statement: This study was conducted according to the Guide for the Care and Use of Laboratory Animals of the National Institutes of Health and Institutional Animal Care and Use Committee (IACUC) guidelines. Mount Sinai West's Institutional Animal Care and Use Committee approved the protocol.

Informed Consent Statement: Not applicable.

Data Availability Statement: The data presented in this study are available on request from the corresponding author.

Conflicts of Interest: The authors declare no conflict of interest. 


\section{References}

1. Mirbolouk, M.; Charkhchi, P.; Kianoush, S.; Uddin, S.M.I.; Orimoloye, O.A.; Jaber, R.; Bhatnagar, A.; Benjamin, E.J.; Hall, M.E.; DeFilippis, A.P.; et al. Prevalence and Distribution of E-Cigarette Use Among U.S. Adults: Behavioral Risk Factor Surveillance System, 2016. Ann. Intern. Med. 2018, 169, 429-438. [CrossRef] [PubMed]

2. Huang, J.; Feng, B.; Weaver, S.R.; Pechacek, T.F.; Slovic, P.; Eriksen, M.P. Changing Perceptions of Harm of e-Cigarette vs. Cigarette Use Among Adults in 2 US National Surveys From 2012 to 2017. JAMA Netw. Open 2019, 2, e191047. [CrossRef] [PubMed]

3. Madison, M.C.; Landers, C.T.; Gu, B.H.; Chang, C.Y.; Tung, H.Y.; You, R.; Hong, M.J.; Baghaei, N.; Song, L.Z.; Porter, P.; et al. Electronic cigarettes disrupt lung lipid homeostasis and innate immunity independent of nicotine. J. Clin. Investig. 2019, 129, 4290-4304. [CrossRef] [PubMed]

4. Bhat, T.A.; Kalathil, S.G.; Bogner, P.N.; Blount, B.C.; Goniewicz, M.L.; Thanavala, Y.M. An Animal Model of Inhaled Vitamin E Acetate and EVALI-like Lung Injury. New Engl. J. Med. 2020, 382, 1175-1177. [CrossRef]

5. US Food and Drug Administration. Enforcement Priorities for Electronic Nicotine Delivery System (ENDS) and Other Deemed Products on the Market without Premarket Authorization; DOHAHS, Ed. Available online: https:/www.fda.gov/regulatory-information/search-fda-guidance-documents/enforcement-prioritieselectronic-nicotine-delivery-system-ends-and-other-deemed-products-market (accessed on 20 November 2020).

6. Herrington, J.S.; Myers, C. Electronic cigarette solutions and resultant aerosol profiles. J. Chromatogr. A 2015, 1418, 192-199. [CrossRef]

7. Kucharska, M.; Wesolowski, W.; Czerczak, S.; Socko, R. Testing of the composition of e-cigarette liquids-Manufacturer-declared vs. true contents in a selected series of products. Med. Pr. 2016, 67, 239-253. [CrossRef]

8. Canistro, D.; Vivarelli, F.; Cirillo, S.; Babot Marquillas, C.; Buschini, A.; Lazzaretti, M.; Marchi, L.; Cardenia, V.; Rodriguez-Estrada, M.T.; Lodovici, M.; et al. E-cigarettes induce toxicological effects that can raise the cancer risk. Sci. Rep. 2017, 7, 2028. [CrossRef]

9. Gillman, I.G.; Kistler, K.A.; Stewart, E.W.; Paolantonio, A.R. Effect of variable power levels on the yield of total aerosol mass and formation of aldehydes in e-cigarette aerosols. Regul. Toxicol. Pharm. 2016, 75, 58-65. [CrossRef]

10. Bekki, K.; Uchiyama, S.; Ohta, K.; Inaba, Y.; Nakagome, H.; Kunugita, N. Carbonyl compounds generated from electronic cigarettes. Int J. Environ. Res. Public Health 2014, 11, 11192-11200. [CrossRef]

11. Wu, Q.; Jiang, D.; Minor, M.; Chu, H.W. Electronic cigarette liquid increases inflammation and virus infection in primary human airway epithelial cells. PLoS ONE 2014, 9, e108342. [CrossRef]

12. Chapman, D.G.; Casey, D.T.; Ather, J.L.; Aliyeva, M.; Daphtary, N.; Lahue, K.G.; van der Velden, J.L.; Janssen-Heininger, Y.M.W.; Irvin, C.G. The Effect of Flavored E-cigarettes on Murine Allergic Airways Disease. Sci. Rep. 2019, 9, 13671. [CrossRef]

13. Chen, H.; Li, G.; Chan, Y.L.; Chapman, D.G.; Sukjamnong, S.; Nguyen, T.; Annissa, T.; McGrath, K.C.; Sharma, P.; Oliver, B.G. Maternal E-Cigarette Exposure in Mice Alters DNA Methylation and Lung Cytokine Expression in Offspring. Am. J. Respir. Cell Mol. Biol. 2018, 58, 366-377. [CrossRef] [PubMed]

14. Nguyen, T.; Li, G.E.; Chen, H.; Cranfield, C.G.; McGrath, K.C.; Gorrie, C.A. Maternal E-Cigarette Exposure Results in Cognitive and Epigenetic Alterations in Offspring in a Mouse Model. Chem. Res. Toxicol. 2018, 31, 601-611. [CrossRef]

15. Blount, B.C.; Karwowski, M.P.; Shields, P.G.; Morel-Espinosa, M.; Valentin-Blasini, L.; Gardner, M.; Braselton, M.; Brosius, C.R.; Caron, K.T.; Chambers, D.; et al. Vitamin E Acetate in Bronchoalveolar-Lavage Fluid Associated with EVALI. New Engl. J. Med. 2020, 382, 697-705. [CrossRef] [PubMed]

16. Korsten, K.; Adriaenssens, N.; Coenen, S.; Butler, C.; Ravanfar, B.; Rutter, H.; Allen, J.; Falsey, A.; Pircon, J.Y.; Gruselle, O.; et al. Burden of respiratory syncytial virus infection in community-dwelling older adults in Europe (RESCEU): An international prospective cohort study. Eur. Respir. J. 2020. [CrossRef] [PubMed]

17. Farsalinos, K.E.; Romagna, G.; Tsiapras, D.; Kyrzopoulos, S.; Voudris, V. Evaluation of electronic cigarette use (vaping) topography and estimation of liquid consumption: Implications for research protocol standards definition and for public health authorities' regulation. Int. J. Environ. Res. Public Health 2013, 10, 2500-2514. [CrossRef] [PubMed] 
18. Shachar-Berman, L.; Bhardwaj, S.; Ostrovski, Y.; Das, P.; Koullapis, P.; Kassinos, S.; Sznitman, J. In Silico Optimization of Fiber-Shaped Aerosols in Inhalation Therapy for Augmented Targeting and Deposition across the Respiratory Tract. Pharmaceutics 2020, 12, 230. [CrossRef]

19. Shalaby, K.H.; Gold, L.G.; Schuessler, T.F.; Martin, J.G.; Robichaud, A. Combined forced oscillation and forced expiration measurements in mice for the assessment of airway hyperresponsiveness. Respir. Res. 2010, 11, 82. [CrossRef]

20. Ford, J.G.; Rennick, D.; Donaldson, D.D.; Venkayya, R.; McArthur, C.; Hansell, E.; Kurup, V.P.; Warnock, M.; Grunig, G. Il-13 and IFN-gamma: Interactions in lung inflammation. J. Immunol. 2001, 167, 1769-1777. [CrossRef]

21. Mehra, D.; Geraghty, P.M.; Hardigan, A.A.; Foronjy, R. A comparison of the inflammatory and proteolytic effects of dung biomass and cigarette smoke exposure in the lung. PLoS ONE 2012, 7, e52889. [CrossRef]

22. Schober, W.; Szendrei, K.; Matzen, W.; Osiander-Fuchs, H.; Heitmann, D.; Schettgen, T.; Jorres, R.A.; Fromme, H. Use of electronic cigarettes (e-cigarettes) impairs indoor air quality and increases FeNO levels of e-cigarette consumers. Int. J. Hyg Environ. Health 2014, 217, 628-637. [CrossRef] [PubMed]

23. Czogala, J.; Goniewicz, M.L.; Fidelus, B.; Zielinska-Danch, W.; Travers, M.J.; Sobczak, A. Secondhand exposure to vapors from electronic cigarettes. Nicotine Tob. Res. 2014, 16, 655-662. [CrossRef] [PubMed]

24. Lerner, C.A.; Sundar, I.K.; Yao, H.; Gerloff, J.; Ossip, D.J.; McIntosh, S.; Robinson, R.; Rahman, I. Vapors produced by electronic cigarettes and e-juices with flavorings induce toxicity, oxidative stress, and inflammatory response in lung epithelial cells and in mouse lung. PLoS ONE 2015, 10, e0116732. [CrossRef] [PubMed]

25. Kreiss, K.; Gomaa, A.; Kullman, G.; Fedan, K.; Simoes, E.J.; Enright, P.L. Clinical bronchiolitis obliterans in workers at a microwave-popcorn plant. New Engl. J. Med. 2002, 347, 330-338. [CrossRef] [PubMed]

26. Brass, D.M.; Gwinn, W.M.; Valente, A.M.; Kelly, F.L.; Brinkley, C.D.; Nagler, A.E.; Moseley, M.A.; Morgan, D.L.; Palmer, S.M.; Foster, M.W. The Diacetyl-Exposed Human Airway Epithelial Secretome: New Insights into Flavoring-Induced Airways Disease. Am. J. Respir. Cell Mol. Biol 2017, 56, 784-795. [CrossRef] [PubMed]

27. Park, H.R.; O'Sullivan, M.; Vallarino, J.; Shumyatcher, M.; Himes, B.E.; Park, J.A.; Christiani, D.C.; Allen, J.; $\mathrm{Lu}, \mathrm{Q}$. Transcriptomic response of primary human airway epithelial cells to flavoring chemicals in electronic cigarettes. Sci. Rep. 2019, 9, 1400. [CrossRef] [PubMed]

28. Garcia-Arcos, I.; Geraghty, P.; Baumlin, N.; Campos, M.; Dabo, A.J.; Jundi, B.; Cummins, N.; Eden, E.; Grosche, A.; Salathe, M.; et al. Chronic electronic cigarette exposure in mice induces features of COPD in a nicotine-dependent manner. Thorax 2016. [CrossRef]

29. Chen, E.Y.; Sun, A.; Chen, C.S.; Mintz, A.J.; Chin, W.C. Nicotine alters mucin rheological properties. Am. J. Physiol. Lung Cell. Mol. Physiol. 2014, 307, L149-L157. [CrossRef]

30. Jiang, Y.; Dai, A.; Zhou, Y.; Peng, G.; Hu, G.; Li, B.; Sham, J.S.; Ran, P. Nicotine elevated intracellular Ca(2)(+) in rat airway smooth muscle cells via activating and up-regulating alpha7-nicotinic acetylcholine receptor. Cell. Physiol. Biochem. Int. J. Exp. Cell. Physiol. Biochem. Pharmacol. 2014, 33, 389-401. [CrossRef]

31. Xu, Y.; Li, H.; Bajrami, B.; Kwak, H.; Cao, S.; Liu, P.; Zhou, J.; Zhou, Y.; Zhu, H.; Ye, K.; et al. Cigarette Smoke (CS) and Nicotine Delay Neutrophil Spontaneous Death via Suppressing Production of Diphosphoinositol Pentakisphosphate. Proc. Natl. Acad. Sci. USA 2013, 110, 7726-7731. [CrossRef]

32. Vassallo, R.; Kroening, P.R.; Parambil, J.; Kita, H. Nicotine and oxidative cigarette smoke constituents induce immune-modulatory and pro-inflammatory dendritic cell responses. Mol. Immunol. 2008, 45, 3321-3329. [CrossRef] [PubMed]

33. Alcorn, J.L.; Stark, J.M.; Chiappetta, C.L.; Jenkins, G.; Colasurdo, G.N. Effects of RSV infection on pulmonary surfactant protein SP-A in cultured human type II cells: Contrasting consequences on SP-A mRNA and protein. Am. J. Physiol Lung Cell Mol. Physiol 2005, 289, L1113-L1122. [CrossRef] [PubMed]

34. Foronjy, R.F.; Dabo, A.J.; Taggart, C.C.; Weldon, S.; Geraghty, P. Respiratory syncytial virus infections enhance cigarette smoke induced COPD in mice. PLoS ONE 2014, 9, e90567. [CrossRef] [PubMed]

35. Sussan, T.E.; Gajghate, S.; Thimmulappa, R.K.; Ma, J.; Kim, J.H.; Sudini, K.; Consolini, N.; Cormier, S.A.; Lomnicki, S.; Hasan, F.; et al. Exposure to electronic cigarettes impairs pulmonary anti-bacterial and anti-viral defenses in a mouse model. PLoS ONE 2015, 10, e0116861. [CrossRef] [PubMed]

36. Hijano, D.R.; Vu, L.D.; Kauvar, L.M.; Tripp, R.A.; Polack, F.P.; Cormier, S.A. Role of Type I Interferon (IFN) in the Respiratory Syncytial Virus (RSV) Immune Response and Disease Severity. Front. Immunol. 2019, 10, 566. [CrossRef] 
37. Thwaites, R.S.; Coates, M.; Ito, K.; Ghazaly, M.; Feather, C.; Abdulla, F.; Tunstall, T.; Jain, P.; Cass, L.; Rapeport, G.; et al. Reduced Nasal Viral Load and IFN Responses in Infants with Respiratory Syncytial Virus Bronchiolitis and Respiratory Failure. Am. J. Respir. Crit. Care Med. 2018, 198, 1074-1084. [CrossRef]

38. Merolla, R.; Rebert, N.A.; Tsiviste, P.T.; Hoffmann, S.P.; Panuska, J.R. Respiratory syncytial virus replication in human lung epithelial cells: Inhibition by tumor necrosis factor alpha and interferon beta. Am. J. Respir. Crit. Care Med. 1995, 152, 1358-1366. [CrossRef]

39. Wingerchuk, D.M. Smoking: Effects on multiple sclerosis susceptibility and disease progression. Ther. Adv. Neurol. Disord. 2012, 5, 13-22. [CrossRef]

40. Carlens, C.; Hergens, M.P.; Grunewald, J.; Ekbom, A.; Eklund, A.; Hoglund, C.O.; Askling, J. Smoking, use of moist snuff, and risk of chronic inflammatory diseases. Am. J. Respir. Crit. Care Med. 2010, 181, 1217-1222. [CrossRef]

41. Markowitz, C.E. Interferon-beta: Mechanism of action and dosing issues. Neurology 2007, 68, S8-S11. [CrossRef]

42. Nguyen, T.H.; Maltby, S.; Simpson, J.L.; Eyers, F.; Baines, K.J.; Gibson, P.G.; Foster, P.S.; Yang, M. TNF-alpha and Macrophages Are Critical for Respiratory Syncytial Virus-Induced Exacerbations in a Mouse Model of Allergic Airways Disease. J. Immunol. 2016, 196, 3547-3558. [CrossRef] [PubMed]

43. Neuzil, K.M.; Tang, Y.W.; Graham, B.S. Protective Role of TNF-alpha in respiratory syncytial virus infection in vitro and in vivo. Am. J. Med. Sci. 1996, 311, 201-204. [CrossRef] [PubMed]

44. Bradley, J.R. TNF-mediated inflammatory disease. J. Pathol. 2008, 214, 149-160. [CrossRef] [PubMed]

45. Zamri, F.; de Vries, T.J. Use of TNF Inhibitors in Rheumatoid Arthritis and Implications for the Periodontal Status: For the Benefit of Both? Front. Immunol. 2020, 11, 591365. [CrossRef] [PubMed]

46. Lagente, V.; Le Quement, C.; Boichot, E. Macrophage metalloelastase (MMP-12) as a target for inflammatory respiratory diseases. Expert Opin. Ther. Targets 2009, 13, 287-295. [CrossRef] [PubMed]

47. Chen, S.; Xie, J.; Zhao, K.; Ren, L.; Deng, Y.; Xie, X.; Chen, S.; Xu, H.; Long, X.; Liu, E. LPS aggravates lung inflammation induced by RSV by promoting the ERK-MMP-12 signaling pathway in mice. Respir. Res. 2020, 21, 193. [CrossRef]

48. Long, X.; Li, S.; Xie, J.; Li, W.; Zang, N.; Ren, L.; Deng, Y.; Xie, X.; Wang, L.; Fu, Z.; et al. MMP-12-mediated by SARM-TRIF signaling pathway contributes to IFN-gamma-independent airway inflammation and AHR post RSV infection in nude mice. Respir. Res. 2015, 16, 11. [CrossRef]

49. Marchant, D.J.; Bellac, C.L.; Moraes, T.J.; Wadsworth, S.J.; Dufour, A.; Butler, G.S.; Bilawchuk, L.M.; Hendry, R.G.; Robertson, A.G.; Cheung, C.T.; et al. A new transcriptional role for matrix metalloproteinase-12 in antiviral immunity. Nat. Med. 2014, 20, 493-502. [CrossRef] [PubMed]

50. Chelluboina, B.; Nalamolu, K.R.; Klopfenstein, J.D.; Pinson, D.M.; Wang, D.Z.; Vemuganti, R.; Veeravalli, K.K. MMP-12, a Promising Therapeutic Target for Neurological Diseases. Mol. Neurobiol. 2018, 55, 1405-1409. [CrossRef]

Publisher's Note: MDPI stays neutral with regard to jurisdictional claims in published maps and institutional affiliations.

(C) 2021 by the authors. Licensee MDPI, Basel, Switzerland. This article is an open access article distributed under the terms and conditions of the Creative Commons Attribution (CC BY) license (http://creativecommons.org/licenses/by/4.0/). 